\title{
Pilares e vanguarda da Nutrição alicerçados ao longo dos ciclos da vida
}

A nutrição como ciência, política social e/ou profissão no cenário mundial é um fenômeno relativamente recente, característico do século XX. No Brasil, teve seu início em 1939, com a abertura dos Cursos Técnicos em Nutrição e Dietética na Superintendência do Ensino Profissional do Estado de São Paulo e de Auxiliares de Alimentação da Escola Central de Nutrição do Estado da Guanabara, concomitante ao primeiro curso para formação de nutricionistas, no Instituto de Higiene, atualmente Faculdade de Saúde Pública da Universidade de São Paulo. Já a regulamentação da profissão e seu exercício ocorreram em 24 de abril de 1967, pela Lei n. 5.276, sancionada pelo então Presidente da República General Artur da Costa e Silva1.

Chegamos em 2014 com a recente publicação da revista Nutrición Hospitalaria, editada pela Sociedade Espanhola de Nutrição Enteral e Parenteral, com seu crescente destaque no cenário internacional, que desvenda a produção científica ibero-americana da nutrição a partir da investigação de 789 referências, com Índice Price de 43,9\%, provenientes das bases de dados PubMed (MeSH) e Google Scholar. Por meio de técnicas bibliométricas e análise estatística descritiva, constatou-se que a produção científica na Área de Nutrição se mantém pujante e atual, tendo o inglês como idioma principal de publicação $(90,8 \%)$, seguido do castelhano $(2,3 \%)$, alemão $(2,2 \%)$ e português (1,9\%). Embora provenientes de 57 nacionalidades distintas, destacam-se as publicações de origem estadunidense $(26,4 \%)$, com maior fator de impacto dentro da temática de abrangência das Ciências Nutricionais e Oncologia, seguida pela Gastrenterologia e Cirurgia. Quanto à procedência da afiliação institucional dos autores, destacam-se as universidades $(48,3 \%)$, seguidas dos hospitais $(14,6 \%)$, e, de forma menos expressiva, os centros de investigação, os organismos oficiais, as empresas e sociedades científicas, perfazendo um total de $100 \%$. Considerando as universidades, são notáveis as posições da Universidade de Lisboa, ocupando o primeiro lugar no ranque, e a Universidade de São Paulo, em sétimo lugar, indicando claramente a importância dos países ibero-americanos e com idioma em comum².

Esta edição vem ao encontro do recente cenário mundial de vanguarda da nutrição, alicerçada nos pilares delineados no Brasil quando do seu surgimento pela Medicina, atrelada à área da Medicina II pela CAPES e alcançando, em 2011, sua independência acadêmica com a criação da Área da Nutrição. Dados da produção acadêmica dos 15 programas de Pós-Graduação no triênio de 2007-2009 indicam que foram publicados 2.168 artigos, dos quais 10,9\% em Qualis-Capes A1 e A2 e 48,8\% em estratos B1 a B3. Concomitantemente, ocorreu incremento de 
$37,4 \%$ de docentes permanentes nos programas de Lato e Stricto sensu. Quanto às áreas de atuação do nutricionista, conforme Resolução 380/05, segundo tabulações de séries históricas do Diretório de Grupos de Pesquisa (DGP) da CAPES, constatou-se que os núcleos de saberes com maior número absoluto são Alimentação e Nutrição em Saúde Coletiva ( $=29$ ), Nutrição Clínica $(n=24)$, Nutrição e Alimentos $(n=11)$ e, finalmente, Alimentação e Nutrição em Produção de Alimentos $(n=5)$. Tais campos científicos são enfatizados ao longo dos artigos selecionados na presente edição aliados aos diferentes ciclos da vida ${ }^{3}$.

Gostaríamos de agradecer aos autores, que se comprometeram a fazer todas as adequações exigidas pelo processo da publicação científica. Agradecemos, também, e em especial, à coordenadora científica da edição, Profa. Dra. Luciana Rossi, pelo seu envolvimento no processo de delineamento deste número.

\section{Leo Pessini* \\ Luciana Rossi**}

\section{REFERÊNCIAS}

1. Rossi L. Nutrição em academias: do fitness ao wellness. São Paulo: Roca; 2013.

2. Franco-Pérez AM, Sanz-Valero J, Wanden-Berghe C, Melian-Fleitas L. La producción científica ibero-americana em ciencias de la nutrición: la indización en PubMed y Google Scholar. Nutr Hosp. 2014;30(5):1165-72.

3. Kac G, Proença RPC, Prado SD. A criação da área "nutrição" na Capes. Rev Nutr. 2011;24(6):905-16.

* Pós-Doutor pela Universidade de Edinboro - Instituto de Bioética James F. Drane, Pensilvânia, EUA. Doutor em Teologia/Bioética. Pós-graduado em Clinical Pastoral Education and Bioethics at St Luke's Medical Center. Docente do Programa Stricto sensu em Bioética (Mestrado, Doutorado e Pós-Doutorado) do Centro Universitário São Camilo-SP, Brasil. E-mail: pessini@saocamilo-sp.br

** Doutora em Nutrição Humana Aplicada pela USP - PRONUT (FSP/FCF/FEA). Coordenadora da Especialização em Nutrição Esportiva em Wellness do Centro Universitário São Camilo. E-mail: Irossi@usp.br 